Nuntius Antiquus, Belo Horizonte, v. 13, n. 2, p. 225-240, 2017

\title{
A vigilância: exercício paradoxal da liberdade
}

\section{The Surveillance: Paradoxical Exercise of Liberty}

\author{
Walter Romero Menon Jr. \\ Departamento de Filosofia \\ Universidade Federal do Paraná, Curitiba, Paraná / Brasil \\ romeromenon@yahoo.fr
}

Resumo: Este ensaio busca analisar acerca do modo como dois princípios fundamentais que definem os regimes democráticos, a liberdade e a igualdade, encontram-se eminentemente ligados à necessidade de dispositivos de controle social e de vigilância. Nossa hipótese é de que quanto mais se pensa o modelo democrático segundo a radicalização desses princípios, mais, paradoxalmente, os dispositivos de controle e de vigilância são pensados como necessários à manutenção dos mesmos princípios. Nesse caso, tal necessidade se expressaria em termos de distribuição igualitária da responsabilidade pelo controle e pelo vigiar, tipificando, desse modo, ações passíveis de serem consideradas representativas das democracias de inspiração liberal.

Palavras-chave: democracia; paradoxo, sociedade de controle, vigilância.

Abstract: This essay seeks to analyze how two fundamental principles of democratic regimes (freedom and equality) are very linked to the need for social control and surveillance devices. Our hypothesis is that the more the democratic model is considered according the radicalization of these principles, the more, paradoxically, control and surveillance devices are thought to be necessary to preserve the same principles. In this case, such necessity would be expressed in terms of the equal distribution of responsibility for control and vigilance, as a kind of actions that could be considered representative of democracies of liberal inspiration.

Keywords: democracy; paradox; society of control; vigilance. 


\section{Introdução}

Cada vez mais, sob o pretexto de que a preservação dos espaços caros à ordem democrática é diretamente proporcional a altos níveis de segurança, a presença de dispositivos de vigilância se vê continuamente reforçada por discursos que a legitimam. $\mathrm{O}$ argumento é de que tais dispositivos, se ainda não são eficazes na previsão e no controle da violência, serão em um momento futuro. Em outros termos, seguindo essa tese, se aventa a hipótese de que estaríamos adentrando cada vez mais em um modelo de sociedade de controle, centralizado, cuja eficácia não depende apenas do desenvolvimento de novas tecnologias de vigilância e seu uso massivo mas também da crença de que quanto maior o controle, maior é o sentimento de preservação dos valores democráticos (FOESSEL, 2010).

Subjacente a esse estado de coisas, constata-se, inversamente, a crença forte no modelo globalizado de democracia neoliberal como representativo, por excelência, dos valores que compõem o ideário democrático: os princípios de liberdade e igualdade encarnados na autonomia própria ao indivíduo. Aqui se encontra invocado um suposto princípio de igualdade que em muitos sentidos poderia ser entendido como representativo de um uso terminológico semanticamente inflacionado, ou em boa parte distorcido, que tenderia a refletir a ideia geral de que em uma verdadeira ordem democrática não pode haver instâncias superiores às regras pelas quais tal ordem se materializa. Sugere-se, ademais, que esse igualitarismo radical encontra-se representado em um modelo de sociedade, no qual o papel do Estado, em termos sociopolíticos, estaria dirimido a ponto de se igualar a qualquer outra instituição que se considere minimamente representativa dos direitos do indivíduo. Liberdade, nesse sentido, pressupõe, na declinação de todos os modos de se conceber o indivíduo, a realização imaginária de todos os seus desejos; estes, por sua vez, são necessariamente pensados e vividos como expressão de uma ordem sociopolítica ideal, nuclear na concepção de um modelo ultraliberal de sociedade. Em outras palavras, se trata aqui de um individualismo imaginário, absoluto, que se alimenta de uma concepção de liberdade igualmente pensada em termos absolutos que, finalmente, se resume a 
questões de propriedade. Ser ou não ser proprietário, conservar e proteger sua propriedade, e assim por diante. O Estado, instituições, pessoas físicas, todos são considerados e tratados segundo a perspectiva do indivíduo.

Com base nessas constatações, gostaria de esboçar duas hipóteses centrais. A primeira é a de que é possível que esse ideal de liberdade "radical" seja um descendente legítimo dos valores fundamentais da democracia tais como estão expressos em sua matriz histórica, e que a ordem democrática historicamente comportaria uma demanda por controle social exercida pelo Estado. Isto é, o controle exercido pelo Estado sobre a sociedade não seria de maneira alguma alheio à ordem democrática na sua estrutura. Caberia a ele assegurar a preservação das normas e regras sociais representativas dos valores democráticos, por meio de técnicas de controle social. Na sua versão ultraliberal, esse controle e sua tecnologia seriam apenas descentralizados.

Nossa segunda hipótese, conforme a primeira, é a de que o horizonte conceitual deste controle, no horizonte das democracias ultraliberais, pressupõe que a vigilância social seja não apenas desejada como valor mas exercida por todos contra todos. Nesse sentido, o que a ausência do Estado centralizado significava em Hobbes, a anarquia, se torna prescrição. Esse horizonte conceitual é, enfim, o da democratização do controle social. Em outros termos, à ideia cada vez mais ordinária de que é um mal para a democracia que instâncias sociais centralizadoras de poder, o Estado, por exemplo, devem ter o privilégio de impor a ordem, a constatação de uma inovação significativa de dispositivos de vigilância, com base no argumento da prevenção contra a ação violenta de agentes antidemocráticos, deve, antes de qualquer coisa, ser entendida na perspectiva da democratização das responsabilidades. Isto é, todos devem, de maneira igualitária, incorporar a necessidade de segurança e controle social às suas vidas. Tal situação resulta da crença no seu imperativo como fundamental à ideia de indivíduo. Entidade sociopolítica abstrata, o indivíduo funcionaria como categoria simbólica que encarnaria idealmente, isto é, de maneira radical, os valores e princípios democráticos de liberdade e igualdade. Se alguém pode se manifestar plenamente, em todo seu potencial de opinião, mobilidade, desejo, e assim por diante, 
esse alguém é a expressão de uma individualidade e, por conseguinte, de uma sociedade de fato democrática, ou seja, uma sociedade em que, efetivamente, os valores democráticos que o indivíduo encarna estão preservados. Evidentemente temos aqui uma circularidade. De um lado, tal circularidade representa a falta de fundamento histórico e político desta "expressão"; de outro, aponta para o fato de que a democracia se reflete e se entende cada vez mais segundo o incentivo e o exercício da individualidade.

\section{0 modelo do sicofanta}

Tomemos a questão dos dispositivos tecnológicos de vigilância nas sociedades democráticas contemporâneas. Eles conservam em parte, como modelo conceitual, o panóptico, tal como pensado por Michel Foucault que se encontra na estrutura de controle que vai desde as guaritas de vigia até as câmeras de vigilância e as escutas. Pode-se pensar que algo diferente se passa quando atingimos o estágio do controle biométrico, do escâner nas fronteiras, das tecnologias de rastreamento por satélite e das que traçam o perfil dos usuários da internet, celulares, e assim por diante. Acredita-se não no esvaziamento ou na dissolução da dimensão centralizante e opaca da torre de vigilância, mas no reforço desse poder central por meio de uma miríade de dispositivos e pontos de recepção, troca e armazenamento de informação. Se um tal estágio de sofisticação de controle, que se pressupõe hegemônico e, em grande parte, intrínseco à vida em sociedade, não escapa ao modelo do panóptico, em pelo menos um de seus sentidos, qual seja, aquele pautado pela ideia do autocontrole, ele, todavia, aponta para um processo de descentralização. Podemos localizar a potencialidade desse processo na consideração de Michel Foucault: "O panóptico é um aparelho de controle sobre seus próprios mecanismos” (FOUCAULT, 1975, p. 238). Esse domínio sobre os próprios mecanismos de vigilância vai encontrar sua expressão máxima no controle dos espaços públicos e privados, pelos próprios indivíduos que, por serem usuários desses espaços, o representam. A responsabilidade compartilhada se pretende justificada pelo fato de que a necessidade de assegurar, contra inimigos internos e externos, a 
ordem social que, efetivamente, constitui esses espaços como espaços democráticos é uma necessidade de todos.

$\mathrm{Na}$ busca por se legitimar o discurso de que a segurança e o controle social são responsabilidades de cada indivíduo — no sentido de serem necessários à preservação dos valores caros à democracia, tais quais os de autonomia e de direito à privacidade - , pede-se o sacrifício desses mesmos valores. A guerra de todos contra todos, que deveria ser prevenida e interdita pela ameaça do uso da violência pela instância superior do Estado, transforma-se em um dever de todos em vigiar a todos, segundo um princípio de igualdade e sob o pretexto de preservar os espaços de liberdade. Essa estrutura paradoxal aparece intrínseca à própria ordem democrática idealizada, se não em sua fórmula de origem, pelo menos no modelo republicano romano sublimado na idealização revolucionária de inspiração rousseauista, que pode ser entendida como a matriz do tipo de radicalização dos valores democráticos.

Gostaria de evocar a cena primitiva dessa democracia radical em um momento, analisado pelo filósofo francês Claude Lefort, do discurso de Robespierre durante o julgamento de Danton, no auge do Terror. Como se sabe, ao defender a execução de Danton, Robespierre pretende a defesa da não excepcionalidade de Danton, ou de qualquer outro, diante do tribunal revolucionário, sob o pretexto de que uns seriam mais preciosos que outros à causa da revolução. Em uma brilhante construção argumentativa, e em grande parte retórica, Robespierre aponta para o fato de que se Danton for absolvido, o "privilégio" de uns sobre outros se substituirá ao princípio sustentáculo da revolução: a igualdade. A tese da excepcionalidade faz com que se levante a suspeita de que o inimigo do povo esteja no seio da própria assembleia reunida. Robespierre parte da premissa de um princípio de identidade entre o povo, a Assembleia, os Comitês de salvação pública, a justiça e, finalmente, ele próprio como representante do povo, para, finalmente, levantar a suspeita sobre a própria assembleia e exigir, em nome do princípio da igualdade, que todos devem vigiar todos (exercício do princípio de igualdade) para que não se destruam as bases institucionais da revolução. Imbuído da crença fundamental na unidade, sustentada pelo princípio de igualdade, entre 
cada uma das instâncias citadas, pronuncia a seguinte frase perante a assembleia: "a inocência jamais teme a vigilância pública". Ao proferir essas palavras, interpreta Lefort,

Robespierre não somente evoca a vigilância sobre os comitês, mas a vigilância sobre cada um por todos, incorporando todos, incorporando a Assembléia, assinalando o grande olho da Assembléia, ou melhor ainda o olho do povo com o qual vem a coincidir o olho de Robespierre que se torna órgão da visão pública. Ele mesmo é um indivíduo entre outros aos olhos vigilantes de seus colegas. (LEFORT; p. 85, 1991)

A instituição republicana assume aqui, como seu princípio, a igualdade de todos os membros da assembleia perante o tribunal revolucionário, no qual se encontraria, necessariamente, manifesta a igualdade de todo cidadão. Sendo assim, o terror é a ditadura da justiça e o gládio da lei; o terror está impresso na liberdade. Por isso o cidadão Robespierre é o escravo desta. Nessa cena, embora não seja uma menção direta, esconde-se um fenômeno de origem democrática, quer dizer, da instituição democrática ateniense, tornado princípio universal: a sicofantia.

Segundo o historiador Domenico Musti (MUSTI, 2013), um procedimento típico da instituição jurídico burocrática da democracia ateniense era a necessidade e legitimação de instâncias de controle caracterizadas pelo exame e cumprimento minucioso da lei, assim como pelo exercício da calúnia e da delação. Podemos pensar que traços deste fenômeno denominado sicofantia podem ser encontrados, no limite do anacronismo, incorporados à noção de igualitarismo radical que guia 0 discurso de Robespierre. Não é por acaso que a primeira medida dos trinta tiranos em Atenas foi combater a sicofantia, pois havia na sua composição uma tendência a ser descentralizada. Não é difícil também imaginar que para o funcionamento dessa atividade era imprescindível dispor de um aparato e de instrumentos que permitissem recolher informações relevantes acerca dos suspeitos de infringir a lei, e que o controle sobre tal aparato escapava ao poder central.

O que assinala o discurso de Robespierre não é o exercício puro e simples da sicofantia como essencial à República, mas, sim, 
que para ser representativa, nada nem ninguém poderia estar acima da República representada pelos comitês de salvação pública, pela máquina burocrático-jurídica regida pelo terror. $\mathrm{O}$ funcionamento dessa máquina, o terror, sobre o qual repousa a democracia, depende de que todos sejam representantes dos seus valores e, portanto, todos vigiem e delatem o menor sinal de quebra da ordem democrática. É nesse sentido também que vale a frase de Robespierre: "a inocência jamais teme a vigilância pública" (LEFORT, 1991). Público se refere a, de fato, todos os presentes que representavam o povo, e por extensão o próprio povo. Portanto, o que se tem aqui é a fé de que o regime republicano estabelece e propõe, ou determina os valores e os princípios nos quais cada um deve ser ver representado. É o regime que promoveria a liberdade e a igualdade, por direito, entre os homens.

Cabe lembrar, de maneira sucinta, que, para a República Romana, eram iguais os homens livres, e liberdade, em grande medida, significava ter o direito, por filiação e herança, a ser representado e a defender-se de uma acusação frente a um tribunal (GRIMAL, 1990). Outrossim, como descreve Rancière (RANCIÈRE, 2005), na ordem democrática grega, ser livre para participar da política da cidade implicava ser cidadão, membro de um demos e respeitar a hierarquia constituída pela antiguidade. Raramente alguém se tornava cidadão. A cidadania era atribuída por nascimento, raramente por naturalização na democracia ateniense do século IV. (HANSEN; p. 94, 1999) Além disso, mesmo que o acesso ao poder se desse por intervenção do "acaso", tendo em vista o processo eletivo ser feito por sorteio, não se subvertia a posição de governantes e governados; os que tinham a possibilidade de governar, por direito, instituíam e, eventualmente, representavam o regime. Ou seja, o regime, tanto em um caso como em outro, não outorga ou promove a liberdade e a igualdade para todos, como seria de se imaginar em uma versão mais moderna, como a desejada e sonhada pelas gerações pré e pós-revolucionárias na Europa e nas Américas. No entanto, uma coisa parece constante: a necessária instituição de mecanismos e de instrumentos de controle social que se acomode às exigências democráticas. $\mathrm{O}$ terror foi, sem dúvida, pensado como um desses meios representativos e, portanto, legítimos de defender 
e perpetuar os valores democráticos, por mais absurdo que isso possa parecer. Na medida em que se busca sua legitimidade, ao se defender o terror como parte essencial do processo de instauração de uma ordem social mais justa, ele se confunde com os próprios valores da República.

Longe de querer levantar a hipótese da perpetuação de uma espécie de terror mitigado nas democracias liberais contemporâneas, ou de que elas são herdeiras diretas do radicalismo revolucionário, o intuito em mencionar essa cena como originária da democracia baseada na transformação de um fenômeno (o exercício da vigilância e do controle) em princípio universal tem por objetivo, antes de qualquer coisa, aludir a uma matriz conceitual que estaria na base da maneira radical ou excessiva pela qual a necessidade de segurança é entendida como essencial para a preservação dos valores democráticos e como é necessário, ao se pensar as democracias contemporâneas, entender a responsabilidade da vigilância encarnada na figura do indivíduo.

\section{Monstros e protótipos}

É, queremos crer, no horizonte de um modelo social, em maior ou menor grau, comprometido com certos padrões de gestão ultraliberais, que se reivindica a legitimidade da aplicação radical dos princípios democráticos na forma de um individualismo ideal. Por conseguinte, o teor do discurso no qual se encontra evocada a responsabilidade individual pela segurança da sociedade, cabe insistir, é o mesmo que alimenta a base das democracias contemporâneas, qual seja, o do individualismo associado ao igualitarismo: todos têm direito à autonomia, ao direito fundamental à propriedade, mobilidade, entre outros. A esses valores, entendidos como essenciais à democracia, não se opõe a ideia de controle social. Pelo contrário, percebe-se a violência contra tais valores como violência a que o indivíduo se expõe quando se encontra fora dos espaços vigiados. Tais espaços são necessários à integridade dos indivíduos, e esses à integridade da democracia. Os dispositivos de segurança são a garantia não apenas da integridade física ou psicológica do indivíduo mas também, e sobretudo, da integridade simbólica dos espaços nos quais deve obrigatoriamente ser possível a autonomia individual. A multiplicação 
dos dispositivos de segurança nos espaços sociais se faz de tal maneira necessária, que a existência de tais espaços depende intrinsecamente desses aparatos. Nesse sentido, não parece exagerado afirmar que o fim último da sociedade deve ser o de exercer a vigilância e o controle sobre si mesma; a vigilância, o controle de cada um sobre si e sobre o outro, deve ser vista como o autocontrole que tipifica a autonomia do indivíduo no sentido de reforçar a imagem do individualismo como símbolo máximo da liberdade e, portanto, da democracia.

Os espaços sob vigilância, dessa forma, são aqueles nos quais a mobilidade individual encarna-se no jogo de experiências e ações determinadas pela realização do desejo de cada um, como realização simbólica do desejo que se pauta pela intenção normativa da sociedade. Nesses espaços, por mais diferenciadas que sejam em suas expressões individuais, tais ações são entendidas e validadas pelo que possuem de comum, ou seja, pelo imperativo social de realização do desejo que as regem, identificado à ideia de liberdade. Desejos materializados em ações, à medida que representem os valores da sociedade democrática liberal, além de terem o direito à sua realização garantido, também devem ser necessariamente estimulados. É nesse sentido que espaços nos quais são simbolizadas as diversas formas de realização dos desejos aparecem como o lugar natural do exercício da liberdade. A relação entre espaço vigiado e representação social da liberdade ultrapassa e engloba a dimensão da segurança, tornando-se o fundamento mesmo da democracia (FOESSEL, 2010). Quanto maior é o controle sobre os espaços, sobre os corpos, sobre ações, maior é a possibilidade de se perceber e realizar as experiências e as ações individuais segundo a ótica de um ganho no gradiente da autonomia (realização dos desejos). Quanto mais concreto for o sentimento compartilhado do aumento efetivo desse gradiente, menor será a possibilidade de se questionar o imperativo social de segurança. Dessa maneira, o controle torna-se, sob o capitalismo global, reivindicação de cada um na defesa de um espaço de autonomia compartilhado de maneira igualitária.

Nesse sentido, é universal o direito a obter informação e o dever de fornecer informação sobre qualquer ocorrência ou comportamento que 
implique risco ou ameaça aos espaços de liberdade. O direito à informação sobre os produtos de consumo, sobre horários e funcionamento de vários serviços públicos, espaços de consumo e circulação, e assim por diante, pode ser traduzido como o direito à informação sobre níveis de segurança. $\mathrm{O}$ dever de qualquer indivíduo de informar sobre bagagens ou pacotes abandonados em espaços públicos, ou sobre o comportamento suspeito de determinados grupos ou indivíduos, se dá na continuação de um mesmo esquema conceitual básico. A necessidade de segurança se estende ao âmbito da intimidade, na qual a vigilância e o controle do próprio corpo, sob o pretexto de preservar sua integridade, nada mais são que o resultado evidente das informações colhidas sobre o nível de segurança de certos produtos, serviços e espaços. O que está em jogo aqui é o acesso democrático à informação: é esse acesso que permite o controle efetivo, legitimado pela defesa dos princípios democráticos de todas as esferas sociais, com o propósito de normatizar comportamentos. (FOESSEL, 2010).

Veja-se o caso do acesso a informações capturadas da internet, de celulares, etc., por meio de sistemas de segurança cada vez mais invasivos. Tais informações são traduzidas em termos de padrões de comportamento social. Saber quais os lugares frequentados, com qual constância, e quais os produtos consumidos em quais locais tem por fim, entre outras coisas, determinar um padrão comportamental desviante. Devido a sua eficácia em detectar e neutralizar tais comportamentos, o uso dessa tecnologia de busca e registro dos "traços" deixados pelos usuários na rede, somada à das câmeras de vigilância de rua, de prédios residenciais, ou públicos, inscrevem-se na representação simbólica do corpo de cada indivíduo como imprescindível à sua integridade. $\mathrm{O}$ fim, portanto, dos dispositivos de vigilância, além de ser o de impedir a degradação dos espaços sociais, antecipando os possíveis focos de violência, consiste em identificar os agentes que estão na origem destes focos.

A identificação se faz segundo determinados protótipos: o do delinquente de rua, do viciado em crack, do traficante, do terrorista, do manifestante político, etc. Esses tipos fornecem um repertório de imagens indiciais do que deve ser temido. Assim, buscam-se similaridades entre indivíduos e ações com os protótipos fornecidos pelo repertório 
imaginário disponível. Identificar o inimigo implica, em última instância, engendrá-lo como uma exageração das características do indivíduo idealizado; por exemplo, a exageração da autonomia do indivíduo a tal ponto que esta torna-se uma representação da liberdade absoluta, ou seja, descontrolada e monstruosa. (FOUCAULT, 1975). Dois tipos de procedimentos retóricos estão implicados no monstruoso de maneira geral: este se produz por efração, por falta ou por exageração. Este último rege o monstro social determinado pelo descontrole, na medida em que a exageração da liberdade incorre em um perigo ao voltar-se contra a ordem social que garante o próprio exercício da liberdade. Ao chocar-se contra o princípio pressuposto de governabilidade da autoridade estabelecida, proporciona um amálgama de matriz simbólica: aquele entre o protótipo do monstro social e aquele outro da massa ameaçadora que data do princípio da era industrial, amorfa, sem face. De certo modo, esse amálgama entre o protótipo do inimigo da sociedade organizada e a massa sem rosto simboliza, na era pós-industrial, para além do estereótipo dos grupos identificados à periferia pobre, aos desempregados, a certas minorias sociais ou étnicas, também todo aquele cujo comportamento é desviante da norma. O que se teme é uma liberdade não controlada e, portanto, imprevisível.

\section{Desidentificação necessária}

Se, por um lado, de fato, todos estamos submetidos a dispositivos de vigilância, por outro, nem todos se veem como seu objeto, sobretudo aqueles cuja necessidade de segurança comanda seu desejo de submissão a tais dispositivos. Tomemos o exemplo do controle nos aeroportos. Se desejo e aceito passar por todo o ritual de controle para embarcar, é porque, de alguma maneira, não me vejo como objeto desse controle que é sempre, para mim, dirigido a um outro que materializa, de alguma maneira, algo daquele repertório que indica qual o inimigo prototípico. Com base na imagem ideal da minha individualidade, dependente da imagem da liberdade democrática preservada pelos sistemas de segurança, é que posso não me identificar com o objeto de vigilância e, ao mesmo tempo, identificá-lo ao terrorista. Todavia, a não identificação 
só é possível porque, justamente, compartilho com o terrorista a maior parte das suas características. Acontece que por serem, na imagem do terrorista, deformadas, exageradas, isto é, monstruosas, tais características se mostram como indícios de um agente que se apresenta como risco eminente à normatização, isto é, indícios de comportamentos desviantes potenciais que devem ser previstos e anulados.

As redes sociais parecem ser um bom exemplo dessa não identificação. Embora sejam sujeitas à vigilância, o modo como estão estruturadas permite aos mais diversos atores sociais terem acesso e compartilharem o que entendem como informação relevante; há inegavelmente uma margem de liberdade efetiva no uso da informação, o que leva uma boa parte dos usuários a não se considerarem objetos diretos da vigilância. Nessa perspectiva, a liberdade de acesso e troca de informação, bem como a mobilidade virtual e o consumo de produtos via internet, são entendidos como realização de autonomia. E nesse sentido também a autonomia se acomoda perfeitamente à necessidade de controle que se confunde com a própria estrutura das redes. Nesse sentido as redes sociais são exemplares. Uma vez que os indivíduos e as instituições são estimulados a um uso desinibido das redes, aqueles comportamentos que se desviam dos padrões normativos se destacam como exagerações e, por conseguinte, são mais facilmente detectados e punidos pelos próprios usuários e pelos administradores das redes.

\section{As redes sociais}

Um outro indício de que valores democráticos, controle social e sistemas de vigilância se imbricam no contexto das democracias que estamos analisando é o fato inegável que, de maneira recorrente, tanto a exposição dos dispositivos de controle como a exposição das informações consideradas centrais nas estratégias de segurança são entendidas como fundamentais para a manutenção da liberdade. Tomemos o exemplo do uso das redes sociais, dos blogs e de outros meios para disponibilizar informação. O seu uso aponta para o fato de que esses meios são instrumentos indispensáveis para o exercício do controle sobre os próprios sistemas de vigilância. Independentemente da sua 
fiabilidade, o acesso a tais informações e às ações daí decorrentes podem ser tomados como símbolo de resistência a qualquer sistema de controle social identificado como abusivo.

Se é verdade que, por vezes, o exercício da autonomia, da liberdade, se apresenta na forma de confronto entre os usuários e dispositivos de controle, sujeitos à especificidade técnica da internet, não é menos certo que a indeterminação do confronto se dê, em grande medida, no plano da representação simbólica dessa especificidade instrumental: toda ação política e social que pretende ser, ou que, de fato, é consequência do uso das informações disponíveis em tais meios encontra-se, pois, na continuidade entre o seu caráter técnico-instrumental e o que este permite simbolizar em termos de liberdade. Isso ocorre mesmo que tal continuidade apareça sob a forma do confronto. A disponibilidade, ou seja, as possibilidades de utilização do objeto técnico', que é a rede entendida em seu caráter instrumental, apontam para a esfera de possibilidades simbólicas aí representadas: o instrumento pode ser transformado e orientado de acordo com as intenções do usuário e a sua capacidade em conhecer e dominar o funcionamento do instrumento. É nesse sentido que ele passa a ser entendido como meio de autonomia.

Não se pode negar a eminente possibilidade da interferência de qualquer um sobre os dispositivos de segurança que se utilizam de informações privilegiadas para identificar os comportamentos desviantes. Em boa medida, tal interferência acaba por atingir a crença de que esses dispositivos representam a garantia de certos valores democráticos.

\footnotetext{
${ }^{1}$ A noção de objeto técnico foi cunhada pelo filósofo francês Gilbert Simondon, em sua obra Du mode d'existence des objets techniques, publicada em 1958. O termo "objeto técnico" abarca desde as ferramentas e os instrumentos mais rudimentares até as máquinas mais complexas. Objeto técnico concreto, segundo Simondon, seria análogo a um objeto, ou sistema natural. A coerência interna, relações de causa e efeito entre suas partes que se realiza circularmente incorporaria uma parte do meio externo (SIMONDON, 1958, p. 47-48). Penso ser esse o caso dos dispositivos de comunicação, tais quais os smartphones, tablets e outros. No caso, portanto, desses dispositivos, tanto a coerência interna entre as partes quanto a relação com o meio externo correspondem à circulação de informações e sua relação com as redes sociais, nas quais os usuários funcionariam como agentes dessa relação.
} 
Considere-se, por exemplo, a comunicação agilizada pelas redes sociais com o propósito de mobilizar e organizar manifestações no momento em que estão acontecendo; ou ainda, a capacidade de promover e veicular certos debates centrais no cenário político segundo os quais movimentos sociais são criados e ações políticas com impacto direto sobre a sociedade são deflagradas; podemos pensar também no vazamento de informação privilegiada disponibilizada em sites na internet. A mobilização de todo esse instrumental parece ter, dentre outras funções possíveis, a de simbolizar uma liberdade de ação.

No entanto, retomando nossa hipótese central, a liberdade manifesta-se, primordialmente, quando a autonomia se resume à autovigilância ou à vigilância dos outros. Uma parte importante do que se visa com a vigilância democratizada é passar a imagem de que ela deve ser estendida aos sistemas ou dispositivos de vigilância e controle, e desse modo deve ser vista como um exercício da liberdade. Em outros termos, quando os instrumentos de vigilância e controle não escapam, eles próprios, ao controle e à vigilância realizados nos regimes democráticos, por qualquer um, temos aí simbolizada a igualdade por meio de uma paridade de forças mobilizadas em função da defesa do princípio de liberdade. O imperativo do exercício dessa vigilância por todos deve, necessariamente, ser entendido e vivenciado como a expressão da liberdade. Note-se que a liberdade existe, tão somente, naquilo que a representa, que a simboliza, quer dizer, na plena realização do indivíduo.

\section{6 À guisa de conclusão}

Cabe aqui formular uma última questão: da mesma maneira que a ideia de autonomia, como estamos entendendo aqui, é determinada e determina o comportamento de controle e vigilância sobre, por exemplo, o ambiente, sobre o que consumimos, com quem nos comunicamos, etc., e que isso implica a vigilância sobre nós mesmos e sobre os outros, não seria ela também, pela lógica do custo e benefício que lhe é inerente, expressar, de fato, o ideário democrático e não apenas um conjunto de ideologias mais ou menos coerentes com esse ideário e que representam uma radicalização liberal? 
A ideia inicial deste ensaio é a de que o cerne mesmo da ordem democrática abriga o medo da dissolução dos seus princípios fundamentais, e que, portanto, esta ordem é regida pelo signo da necessidade crescente de segurança e controle, a fim de que tais princípios não se dissolvam. Logo, liberdade, controle e vigilância convivem em uma relação complementar. O que ocorre nas democracias contemporâneas, que seguem o modelo de um liberalismo radical, seria uma exageração dessa estrutura. Isso resulta que o máximo de autonomia a ser conquistada em relação aos dispositivos de vigilância não implica -a sua extinção definitiva.

É provável que, para se pensar a democracia no horizonte da sua dimensão plausível, devamos redimensionar o valor da crença em uma sua essência que, perdida, deve ser recuperada, esteja essa essência representada pela origem histórica de um conjunto de valores e princípios, seja pela crença em um ideal de democracia que, em grande medida, encarnaria a radicalização e consumação desses mesmos princípios e valores.

Talvez a própria noção de liberdade que resta, dentro do horizonte de possibilidades éticas e políticas representativas, deva necessariamente abrigar em seu sentido a concepção fundamental de que ela mesma não pode ser constituída fora de um estado de confrontação expressivo e constante entre os dispositivos de controle e os indivíduos que devem exercer um controle sobre esses dispositivos. Esse sentido de liberdade se materializa nas ações afirmativas que assumem a determinação de controle dos dispositivos. Embora seja determinação sobre os dispositivos de controle, a liberdade não se efetiva apenas em termos de negativa do controle social; o seu horizonte deve ser, com efeito, a responsabilidade de todos sobre todas as ações e práticas comuns. Uma das consequências visíveis seria a de que instrumentos de vigilância e informação estariam, portanto, sempre submetidos à possibilidade de sua visibilidade, tornando-se vulneráveis, quer dizer, sujeitos à exposição e ao juízo público.

Em suma, no campo mais estreito da nossa análise, pensamos que a possibilidade e o dever de vigiar que cada um deve assumir como 
próprio à ideia de preservação dos valores e princípios democráticos não se restringem apenas ao reforço retórico da imagem do indivíduo como consubstancial à própria democracia. Em outros termos, a vigilância de cada um sobre cada um não se limita, necessariamente, a uma posição negativa com relação à hierarquização do controle social e não se resume à preservação da democracia identificada à propriedade, ao direito ao consumo, à autonomia como autorrealização. Ela aponta para um lugar no qual é o exercício da responsabilidade coletiva que, de fato, se impõe como base da democracia.

\section{Referências}

DUCROT, O.; TODOROV, T. Dictionnaire encyclopédique des sciences du langage. Paris: Editions du Seuil, 1972.

FOESSEL, M. État de Vigilance. Critique de la banalité sécuritaire. Paris: Le Bord de l'Eau, 2010.

FOUCAULT, M. Surveiller et Punir. Paris: Gallimard, 1975.

GRIMAL, P. Os erros da Liberdade. Campinas: Papirus, 1990.

HANSEN, M. H. The athenian democracy in the age of Demosthenes: structure, principles and ideology. Oklahoma: University of Oklahoma Press Norman, 1999.

LEFORT, C. Pensando o Político. Ensaios sobre a democracia, revolução e liberdade. São Paulo: Paz e Terra, 1991.

MUSTI, D. Demokrátia: origini di un'idea. Roma: Laterza, 2013.

RANCIÈRE, J. La haine de la democracie. Paris: La Frabrique, 2005.

SIMONDON, G. Du mode d'existence des objets techniques. Paris: Aubier, 1958.

Recebido em 30 desetembro de 2017. Aprovado em 28 de outubro de 2017. 